\title{
Psicopedagogia como fator de treinamento para estudantes de
}

\section{escolas rurais}

La Psicopedagogía como factor de formación para estudiantes de las escuelas rurales

Psychopedagogy as a training factor for rural school students

\section{Natalia Brasilia G.}

Ph.D. Universidade Federal de São Paulo, Cimbote, Perú, https://orcid.org/0000-0003-

0580-3868,nataliabrasiliaa@hotmail.com

\begin{abstract}
Recebido em outubro de 2018 - Aceito em maio de 2019
Formación docente - revista iberoamericana de educación

http://www.revista-iberoamericana.org/index.php/es/index

https://creativecommons.org/licenses/by/4.0/deed.es

e-ISSN: $2737-632 X$
\end{abstract}

Vol - 2 No. 3, outubro - dezembro de 2019

e-ISSN: Em processo

Páginas 51-68

Resumo. O abuso psicopedagógico nos estudantes das escolas rurais do cantão de Salitre é uma realidade papal que não é denunciada. O objetivo desta investigação é determinar as manifestações dos maus-tratos psicopedagógicos, analisando e determinando as crenças culturais que permitem essa prática que ocorre no dia a dia entre professor e aluno. Para isso, foram utilizadas duas pesquisas com 93 especialistas, professores e representantes legais.Os resultados indicam que existem medidas coercitivas nas escolas, dentre as quais se destaca a rigidez do professor por não explicar novamente a turma, elevando o tom da voz como mecanismo. alcançar a atenção constante, generalização, crítica e ridículo de crianças com indisciplina. Por outro lado, os professores criticam os pais ou representantes legais que discordam de qualquer disposição que prejudique seus constituintes e preferem permanecer calados por medo de retaliação dos 
professores. Essa atitude faz com que o problema se torne invisível pela população e legitimamente os maus-tratos. Nesse contexto, é importante que sejam tomadas medidas corretivas por parte dos diretores das instituições, promovendo espaços para socializar os direitos das crianças em relação aos professores, seus representantes e às próprias crianças, e promovendo processos de fortalecimento contínuo que permitam aos professores inovar e ser um facilitador de ensino-aprendizagem. Um sistema tutorial sobre direitos é proposto para os professores incorporarem conhecimento jurídico e social para melhores práticas.

Palavras-chave: Explicações, indisciplina, psicopedagogia

Resumen. El maltrato Psicopedagógico en los estudiantes de las escuelas rurales del Cantón Salitre es una realidad papable que no se denuncia. El propósito de esta investigación es determinar las manifestaciones del maltrato Psicopedagógico, analizando y determinando las creencias culturales que permiten esta práctica que se da en el día a día entre docente y estudiante. Para esto se han utilizado dos encuestas a 93 personas expertas, docentes y representantes legales Los resultados indican que en las escuelas existen medidas coercitivas entre las que se destacan la rigidez del docente al no volver a explicar la clase, elevar el tono de voz como mecanismo para lograr la atención, la generalización, crítica y ridiculización constante a los niños con indisciplina. Por otra parte, los docentes critican a los padres o representantes legales que están en desacuerdo con alguna disposición que lesione a sus representados y prefieren callar por temor a las represalias del docente. Esta actitud provoca que el problema sea invisibilizado por la población y más bien se legitima el maltrato. En este contexto es importante que existan medidas reparatorias desde los directivos de las instituciones promoviendo espacios de socialización de los derechos de los niños, niñas 
hacia los docentes, sus representantes y a los mismos niños y promover procesos de fortalecimiento continuo que permita al docente innovar y ser un facilitador de la enseñanza-aprendizaje. Se propone un sistema tutorial sobre los derechos dirigido a los docentes a fin de que incorporen conocimientos legales y sociales para un mejor ejercicio.

Palabras clave: Tutorias, indisciplina, psicopedagógico

Abstract. School abuse psychologica in schools of Salitre downtown is a reality that is palpable by thousands of children who are educated in. The purpose of this research is to determine the manifestations of psychologica abuse, identifying and analyzing the cultural beliefs that maintain this type of practices and so explain to the day to day in the teachers and students relations. For this researching, we have used two surveys applied to 93 people including experts, teachers and legal representatives. The results indicate that still remain certain coercive and intimidating practices in schools, among are commonly the rigidity of the teacher that negate repeat classes when it is requested by students, raise the voice as a mechanism that students pay attention, the generalization and constant judge advocate of children with indiscipline. Legal representatives for their part have been criticized when they disagree in any school provision, due to; they prefer to remain silent for fear of reprisals by the teacher against of students. This situation causes that the problem is internal, little visualized by the population, who, legitimize the abuse to their children with his attitude. In this context, it is important that exist reparatory measures from the directors of the institutions promoting spaces for socialization of rights to children and their representatives, and persuade that participate in processes of continuous strengthening that allows the educator to innovate and be a facilitator of the teaching-learning. In this sense, proposes a tutorial system designed to teachers on the topic of 
children's rights. It is planned with the purpose to incorporate in them social and legal.

Key words: Tutoring, indiscipline, psychopedagogical

\section{INTRODUÇÃO}

De acordo com o artigo 47 do Código da Infância e Adolescência, abuso é definido como toda conduta de ação ou omissão que cause ou possa causar danos à integridade física, psicológica ou sexual ou à saúde de uma criança ou adolescente, por: parte de qualquer pessoa, incluindo seus pais, outros parentes, educadores e cuidadores. $\mathrm{O}$ abuso infantil é um ataque aos direitos mais básicos de crianças e adolescentes consagrados na Declaração Universal dos Direitos Humanos. O país assinante do Equador compromete-se a adotar medidas legislativas, administrativas, sociais e educacionais para proteger a criança contra todas as formas de dano ou abuso físico ou mental, negligência ou tratamento negligente, maus-tratos ou exploração, incluindo abuso sexual.

Com o tempo, foi detectado que as crianças por razões culturais, sociais e interpessoais sofrem violência na família, na escola e na comunidade. $\mathrm{O}$ aspecto mais complexo do abuso infantil é que a violência ocorre precisamente nos locais que deveriam ser locais de afeto e proteção. Meninos e meninas são especialmente vulneráveis ao abuso porque não têm autonomia para se proteger ou pedir ajuda em situações de violência. Quando a violência ocorre no espaço familiar, a solicitação de ajuda é dificultada pelos altos níveis de dependência afetiva, emocional e econômica que eles têm em relação a quem comete abuso. O abuso infantil é considerado qualquer agressão física, psicológica e sexual causada pelo ato ou omissão de um adulto na pessoa de um menino, menina e adolescente (NNA), afetando seu desenvolvimento e integração na sociedade de maneira saudável. 
A constituição do Equador em seu Art.44 O Estado, a sociedade e a família promoverão como prioridade o desenvolvimento abrangente de meninas, meninos e adolescentes e garantirão o pleno exercício de seus direitos, o princípio de seu maior interesse será atendido e seus direitos prevalecerão sobre os de outros.

6.- Erradicar todas as formas de violência no sistema e garantir a integridade física, psicológica e sexual dos alunos. Os remédios disciplinares tendem a ser amplamente disfarçados nas áreas rurais, devido à percepção da comunidade em geral de que a violência se tornou natural, legitimando muitas formas de maus-tratos. nas escolas rurais. Estudantes, entre as 34 instituições de ensino básico entre escolas e jardins de infância fiscais, localizadas na capital cantonal e em suas paróquias Junquillal, Victoria e Vernaza. A situação de maus-tratos nas escolas públicas é evidenciada pelas múltiplas queixas apresentadas pelos pais e representantes das crianças perante as Organizações de Proteção e Cuidado de Crianças e Adolescentes do cantão. Em nosso país, com tantas leis protegendo os direitos de crianças e adolescentes, ainda não foi possível erradicar o abuso psicopedagógico. É por isso que, para evitar consequências futuras, de ter filhos inseguros, medrosos, irritáveis e sem projeção futura, socialmente isolados, sem apoio e que, como solução para seus problemas, escolhem fugir de casa e do deserto nas salas de aula, é necessário proteger adequadamente seus direitos, conscientizando os professores por meio de um guia tutorial sobre os direitos das crianças e dos adolescentes, direcionado a professores com a colaboração do Conselho Cantonal de Crianças e Adolescentes e da Diretoria Proteção cantonal de direitos.

As organizações que emitem medidas de proteção administrativa geralmente envolvem crianças em processos psicoterapêuticos, a fim de interromper o ato de ameaça, restaurar o direito violado e, em alguns casos, garantir 
reparação pelo conflito vivenciado. Nesse sentido, algumas práticas comuns em professores foram identificadas, incluindo: baixar notas, incentivar agressões em sala de aula, zombar dos defeitos e limitações dos alunos e de suas famílias, punir com regras, puxar os cabelos e ouvidos, exigem pagamento de valores e não permitem que os alunos façam suas avaliações. Uma das principais causas de abuso infantil ocorre devido ao costume e à crença dogmática da transmissão geracional; Muitos dos meninos e meninas, apesar dos maus-tratos que receberam, amam seus pais, parentes e professores, e essa coexistência de violência e amor os faz crescer acreditando que os maus-tratos são aceitáveis. O mesmo ocorre com adultos que podem ter naturalizado o abuso e justificá-lo, produzindo um padrão cíclico, garantindo essa forma de relacionamento por mais gerações e constituindo um fator de risco social.

A falta de defesa, considerada como a falta de autonomia derivada da tenra idade, somada aos altos níveis de dependência emocional, econômica e social de adultos ou instituições, é outro fator de risco a observar que confere vulnerabilidade. Limitando, assim, o desenvolvimento físico, psicológico e social, sendo complexo para lidar com conflitos e dificuldades atuais e futuras que terão que viver nas diferentes etapas do ciclo de vida.

Nesse sentido, a violência exercida nas crianças pode ter como conseqüências não apenas um impacto imediato, mas também de longo prazo, que pode ser permanente e afetar as capacidades de adaptação social do futuro adulto.

Quando uma criança indica ter sofrido algum tipo de abuso, ouça e denuncie, dessa maneira, estratégias de intervenção podem ser criadas nos níveis educacional, familiar e comunitário.

A etapa escolar é o período de atendimento e educação de meninos e meninas, no qual eles incorporam conhecimentos de ciências, aprendem mecanismos de socialização, desenvolvem habilidades cognitivas e volitivas. Durante 
décadas, as escolas foram consideradas a segunda casa de meninos e meninas devido ao seu papel formativo na personalidade, conhecimento e valores. Nesse sentido, alguns professores mantêm práticas coercitivas do passado. A doutrina de "que a carta com sangue entra" e no passado os mesmos pais e representantes autorizaram os professores a "punir seus filhos ou representálos". Apesar do progresso significativo, há áreas esquecidas nas quais a lei que rege os destinos da infância é a do poder do pseudo-conhecimento do professor, que, devido ao seu nível acadêmico, é considerado portador da verdade. Um dos problemas que permanece na educação é a idade dos professores, o que é um problema sério, porque vários deles ensinam há 25 e 30 anos e mantêm seus modelos tradicionalistas e muitos perderam o contexto porque foram treinados para educar. uma geração que não existe mais.

A ignorância ou subavaliação dos professores sobre o código da Infância e Adolescência ancora e perpetua os mecanismos de aprendizado e disciplina baseados em coerção, agressão e punição que supõem que alguém exerça o poder a partir de sua posição de autoridade e outro que deve ser subordinado.

\section{MATERIAIS E MÉTODOS}

Muitas crianças em suas escolas foram vítimas de abuso físico, como: bater com uma régua, dar um tapa, agarrá-lo de repente e tremer, beliscar, puxar as orelhas, jogar borrachas, giz ou marcadores, bater na mesa em voz alta para chamar sua atenção Forçando-o a ficar parado e sem se mexer por longos períodos de tempo, delegando um determinado aluno às vezes chamado de capitão ou presidente da classe para punir e controlar fisicamente seus colegas de classe, abusos psicológicos como: gritar ou ameaçar a criança também ocorrem. Antes de todo o grupo, use o medo da punição como um método para estudar e realizar tarefas, insultá-las por motivos de condição, qualidade do trabalho, aparência, higiene, confiscar e danificar objetos "proibidos" para 
levar à escola, rotular ou espalhar fofocas maliciosas sobre ele, deliberadamente ignorá-lo "de nada para nada" e negar sua ajuda, usar sarcasmo ou desqualificá-lo, punir o grupo pela falta de uma criança solteira, punindo a criança como um "exemplo" para os outros, tornando-o expiado e acusando os outros, negando permissão para ir ao banheiro, vingando-se de brigas com pais ou parentes, negando a partida recesso, entre outros.

Os traços deixados pelo abuso, principalmente os psicológicos, afetarão o resto da vida do aluno.

$\mathrm{O}$ abuso escolar prejudica a psique de meninos e meninas, viola seus direitos, criando insegurança, distúrbios emocionais e comportamentais, baixo desempenho escolar, motivação escolar, abandono e perda do ano letivo.

Apesar do trabalho das organizações e do Estado, o problema do abuso escolar é visível através do número de queixas apresentadas ao Comissário da Família, à Junta Cantonal e ao Centro de Proteção de Direitos no cantão de Salitre. A população está se fortalecendo com seus direitos e esse despertar precisa ser acompanhado de uma perspectiva holística.

O Equador é uma das sociedades mais desiguais do mundo, há evidências de exclusão social, aumento das lacunas na distribuição de renda, aumento do desemprego e subemprego e manutenção de uma estrutura de poder abusiva que se origina na família, passa para o ambiente educacional e subsequente a todo o tecido social.

\section{RESULTADOS}

68\% dos meninos e meninas no Equador (3,5 milhões) vivem em famílias pobres. Essa condição é muito mais grave nas áreas rurais. Em que há falta de recursos e acesso a serviços básicos. 
A educação nas áreas rurais é uma oportunidade para quebrar gradualmente o crescente cinturão da pobreza. Salitre é conhecido como o cantão mais pobre da Bacia do Baixo Guayas, a população em geral tem renda que não atinge o salário básico. Nesse sentido, as escolas fiscais são a única oportunidade que muitos precisam aprender.

A construção do capital montubia concedido ao nitrato implica em percepções sociais transmitidas de maneira geracional e constitui sua identidade cultural. Um dos problemas percebidos no cantão é a subvalorização dos pais na área de educação, proteção e assistência, razões pelas quais as crianças se tornam um grupo de risco e altamente vulnerável.

Quando a violência é vivida na infância, são desenvolvidas estratégias de alívio subsequentes que podem ter consequências negativas a longo prazo, incluindo: diminuição do desejo de aprender ou frequentar a escola, depressão, participação em brigas e comportamentos autodestrutivos. .

O conceito de gênero desempenha um papel importante nos padrões de comportamento e estereótipos; as tradições são frequentemente usadas para justificá-lo.

Estudos insuficientes sobre a questão do abuso escolar nas áreas rurais da costa equatoriana são visíveis nas queixas da comunidade às agências de proteção que implementaram patches coercitivos igualmente abusivos, cujos resultados ainda não são evidentes. Moram. K (2011) em um estudo realizado com famílias na área rural de Salitre conclui:

A socialização é realizada de acordo com os preceitos culturais dos habitantes do setor, que privilegiam o trabalho como um modo de vida e não de educação, diferenciam a criação de filhos e filhas, e aí está a importância de se trabalhar sobre o assunto maus-tratos nas instituições, para que apoiem e não expulsem as crianças com suas regras, crenças e práticas. (P. 120) 
A Convenção sobre os Direitos da Criança é uma declaração assinada pelo Equador que serviu de base para o projeto e a criação de um órgão legal conhecido como Código da Infância e Adolescência.

Isso nos levaria a pensar que a situação atual da infância está protegida, mas não é esse o caso, existem algumas formas de abuso no Equador, sendo as mais freqüentes e menos discutidas as violações sofridas por crianças e adolescentes em suas unidades educacionais.

Embora nas instituições de ensino, algumas condições tenham melhorado com relação ao tratamento digno que deve ser dado aos alunos, mesmo dentro dessa prática é mantida, que em alta porcentagem é invisível ao meio social.

A disciplina no processo de ensino requer uma série de estratégias que respondem às características dos alunos e ao ambiente em que as aulas acontecem.

O planejamento dos processos de ensino-aprendizagem deve incluir uma série de recursos pedagógicos, projetados desde o início do ano letivo, apesar dos mecanismos disciplinares, que respondem principalmente à improvisação e ao humor profissional.

Professores jovens e inexperientes responderão inadequadamente a pouca disciplina ou mau desempenho escolar. Manter uma certa ordem nas aulas e melhorar o desempenho escolar é possível se uma organização anterior for mantida, além de aprender conhecimentos e desenvolver habilidades que permitam aos alunos se interessar.

Parte da formação de professores concentra-se na incorporação do modelo tradicional de ensino que priorizou esses processos de aprendizagem com base no armazenamento de informações e conteúdos e favoreceu a capacidade de reproduzi-los. Geralmente, essas aulas são limitadas a cópia, ditado, revisão e aprendizado mecânico que pouco ou nada envolve o próprio aluno em seu desenvolvimento, sendo este um mecanismo defeituoso, essencialmente limitador e abusivo, que não permite que a criança desenvolva seus 
conhecimentos. habilidades devido à falta de desejo de aprender gerado em muitos por motivação insuficiente.

Atualmente, as teorias educacionais reconhecem a importância da diversidade cultural e linguística da sociedade, o imenso volume de informações que circula no mundo e as diferentes necessidades de aprendizado expressas pelos diferentes grupos de cada sociedade. Isso implica que o professor e o aluno mantenham um papel ativo, reflexivo e de autoavaliação, que ajusta as necessidades de seus alunos de acordo com o currículo atual.

A aprendizagem está relacionada à extensão do conhecimento e seu aprofundamento, permite aproveitar as possibilidades oferecidas pela educação ao longo da vida. Está ligado à aquisição de habilidades que facilitam a resolução de problemas e o trabalho em equipe. Também está relacionado ao desenvolvimento da personalidade e autonomia do indivíduo, do julgamento e da responsabilidade pessoal.

A aprendizagem não é o resultado exclusivo de um número mais ou menos categorizado de operações mentais individuais, mas ocorre fundamentalmente e é mediada pelos processos sociais e culturais em que o sujeito participa, para os quais estuda psicologia do desenvolvimento e construções sociais que emergem dos processos de culturalização e a-culturalização do indivíduo.

As concepções de pobreza-riqueza não estão apenas ligadas aos aspectos econômicos e monetários, mas em termos de tudo o que implica produzir bemestar e uma qualidade de vida decente para todos os seres humanos.

A pobreza no Equador permanece intacta e tende a se expandir, especialmente em áreas marginais rurais e urbanas. As taxas de desemprego e subemprego constituem um problema dilacerante para o desenvolvimento eqüitativo, somado às taxas de corrupção e insegurança jurídica, difícil acesso aos serviços públicos de saúde e educação, colocando um risco alarmante para as gerações atuais e futuras. 
Castanho. O (2005) indica "segundo os estudos da UNICEF, 68\% das crianças equatorianas são pobres e 30\% trabalham em condições adversas, sem salário fixo e sem nenhum tipo de proteção e seguridade social. Além disso, sustenta que 7 em cada 10 bebês nascidos são pobres; duas em cada três crianças estão desnutridas; 100.000 crianças com menos de 5 anos não têm acesso ao primeiro ano do ensino fundamental e mais de um milhão de meninos entre cinco e 18 anos não têm educação. ” (p. 18)

A pobreza afeta negativamente o acesso às oportunidades e opções mais fundamentais para poder viver uma vida digna e livre, na qual o potencial do ser humano é desenvolvido, viver na pobreza significa exclusão.

Um menino ou menina que trabalha constitui um sintoma social; Eles falam não apenas do presente da comunidade a que pertence, mas também do futuro. Essa condição ligada à pobreza e às construções pseudo-culturais ajuda o orçamento e a economia da família a serem fatores de risco e evasão escolar associados a abusos no âmbito doméstico e escolar.

\section{CONCLUSÕES}

Nas áreas rurais, o trabalho das crianças é percebido como uma "responsabilidade"; é comum ver crianças envolvidas no comércio informal, agricultura e pecuária, trabalhando para sustentar suas famílias. Dessa maneira, o conceito de infância é distorcido, assumindo papéis que não correspondem ao seu estágio de desenvolvimento. É comum que muitos deles não percebam o valor da educação e favoreçam o trabalho remunerado, o que os torna mais rentáveis em suas vidas diárias.

A proibição dos custos da educação é uma das principais estratégias e medidas para melhorar as taxas de matrícula e participação. As propinas e outras despesas privadas na escola são percebidas como uma barreira para muitas crianças terem 
acesso e concluir o ensino fundamental. Essas despesas são particularmente onerosas em países onde a pobreza toma decisões dolorosas para famílias e famílias sobre quantas crianças assistirão, quem assistirá e por quanto tempo.

A gratuidade da educação no Equador permitiu a um grupo com poucas possibilidades econômicas de acessar a educação; no entanto, não basta, os problemas de pobreza e violência limitam a renda em alguns casos e em outros casos o apoio no sistema educacional regular.

As políticas gratuitas devem levar em consideração a abolição das propinas escolares e outras despesas domésticas, como textos, uniformes, transporte, especialmente nas áreas menos privilegiadas, incluindo áreas rurais e indígenas.

As necessidades de desenvolvimento educacional não atendidas exigem medidas urgentes que devem ser articuladas com as de médio e longo prazo.

O espaço educacional aparece como um campo complexo, onde se realizam práticas de transmissão de conhecimento, abertas aos processos produtivos, em uma realidade dinâmica que confere aos sujeitos um caráter criativo na práxis cotidiana. A prática de ensino não é resolvida então a partir da mera perspectiva pedagógica, mas requer construção interdisciplinar para sua abordagem.

O estilo acadêmico é caracterizado pelas exposições dos professores, nas quais o conteúdo estabelecido nos livros recebe mais valor do que o que o grupo de estudo conhece. A participação dos membros é artificial, na medida em que somente ocorre a pedido do professor, nos horários e com o conteúdo exigidos. Caso contrário, você não pode participar ou as intervenções são simplesmente desqualificadas.

Esse estilo reforça o senso que os jovens atribuem ao processo educacional, onde eles não sabem, estão apenas espionando os outros.

O conhecimento que eles possuem adquire um lugar hierárquico mais baixo em relação ao conhecimento verdadeiro. Assim, a ideia de si mesmo como ignorante 
ou incapaz é reforçada; Da mesma forma, corre-se o risco de reforçar também uma relação vertical com o educador.

No estilo de controle do grupo, o conteúdo tem um papel secundário, o que motiva o professor a manter o grupo em uma determinada ordem; os alunos praticam regularmente determinados comportamentos sempre cuidando do professor, deixando de lado o processo de aprendizagem do conteúdo. . As aulas acontecem com a aparente supervisão do professor que analisa os cadernos e supervisiona o desenvolvimento das atividades que ele exigiu. Esse estilo reforça uma relação pedagógica vertical, um aspecto muito introjetado nas maneiras pelas quais as crianças experimentam exclusão nos espaços educacionais, de sua própria aprendizagem.

Em resumo, é consolidada uma forma de exercício do poder que não permite o desenvolvimento de uma atitude participativa.

O bom estilo de suposição de tratamento é caracterizado por sempre falar de maneira diminuta com o aluno e usar exemplos fáceis, assumindo que ele o entende melhor. Esse estilo é baseado na concepção dos alunos como falta de ferramentas cognitivas para a aprendizagem.

Um bom tratamento pode ser pervertido na medida em que subestima o tratamento que todos, independentemente de sua idade, merecem.

O aprendizado pode ser considerado como um processo de natureza extremamente complexa, caracterizado pela aquisição de novos conhecimentos, habilidades ou capacidades, e deve ser esclarecido que, para que esse processo seja realmente considerado aprendizado, em vez de uma simples impressão digital ou retenção temporária de conhecimentos. deve ser capaz de se manifestar no futuro e também contribuir para a solução de situações concretas, mesmo diferentes em essência daquelas que inicialmente motivaram o desenvolvimento de conhecimento, habilidade ou capacidade. 
A aprendizagem, embora seja um processo, também é um produto, pois são precisamente os alunos que testemunham especificamente os processos. É importante que o professor, os pais e as pessoas com quem as crianças se desenvolvam e vivam conheçam o potencial e as habilidades da criança. Uma vez que nem todos aprendem da mesma maneira.

O desenvolvimento cognitivo e social das crianças ocorre no decorrer da vida, pelo qual aumentam os conhecimentos e habilidades para perceber, pensar e entender. As habilidades são usadas para resolver problemas práticos do dia a dia.

Philip. R (2000). Na infância, o domínio cognitivo é marcado pela organização de operações concretas. A afetividade e o desenvolvimento social traduzem essa relativa estabilidade das realizações cognitivas e mostram um comportamento aberto e sociável, focado, acima de tudo, no relacionamento com os colegas. (p. \# 384)

$\mathrm{Na}$ fase escolar, as crianças têm uma forte necessidade de se sentirem aceitas e valorizadas. Eles mostram sua capacidade de serem independentes, sendo desobedientes, respondendo (não muito gentis) e rebeldes. Eles preferem vitórias individuais sobre competição. Eles gostam de receber sugestões e são incentivados em vez de competir. Eles ainda buscam a aprovação de adultos, especialmente de seus pais.

Eles começam a assumir a responsabilidade por suas próprias ações. Eles gostam de fazer parte de grupos organizados. Eles preferem estar com membros do mesmo sexo. Eles admiram e imitam jovens mais velhos. Eles começam a ter amigos e a entender o conceito de amizade. Eles querem ser aceitos pelo grupo de amigos.

Se os adultos estiverem dispostos a ouvir as crianças, especialmente quando falam sobre seus medos, e a serem fontes de estabilidade para eles, eles serão 
capazes de lidar com seus próprios problemas muito melhor. As crianças são mais flexíveis se nascerem com um temperamento moderado e tiverem boa saúde mental. Se tiverem a sorte de ter pais fortes, capazes de tolerar a pressão da pobreza e da violência na comunidade, é mais provável que as crianças se tornem adultos felizes e produtivos.

Experiências negativas na infância significam que as crianças são capazes de lidar com a dor e o medo de seus primeiros anos de vida. Para as crianças que vivem em uma atmosfera de pressão e violência, a capacidade de formar relacionamentos e obter dos outros o que lhes falta na família e na comunidade é de grande importância em termos de desenvolvimento saudável.

Para evitar consequências futuras, de ter filhos inseguros, medrosos, irritáveis e sem projeção futura, socialmente isolados, sem apoio e que, como solução para seus problemas, escolhem fugir de casa e abandonar as salas de aula. proteção adequada dos seus direitos é necessária

É por esse motivo que é necessário implementar nas escolas um ciclo de palestras com professores, representantes legais, gestores sobre os direitos e a proteção de crianças e adolescentes, a fim de sensibilizá-los e evitar novas violações, utilizando o também órgãos existentes, tais como: o Conselho Cantonal para a Proteção dos Direitos, o Conselho Cantonal para a Proteção dos Direitos, que, como órgão governante, deve emitir as disposições legais a esse respeito, os Tribunais da Infância e Adolescência.

Também é importante treinar continuamente crianças e adolescentes para que eles saibam quais são seus direitos e quais são seus deveres, para que possam se identificar quando estão sendo maltratados e se comunicar com seus representantes e diretores de instituições de ensino.

Além disso, os departamentos de aconselhamento estudantil, na pessoa do psicólogo clínico, devem realizar terapia de grupo com crianças e 
adolescentes que foram violados por seus direitos, que foram maltratados para reparar os danos causados.

\section{REFERÊNCIAS}

Arés, Patricia. (2006). “Tipología del Grupo familiar”. Ecuador. Universidad de Guayaquil - Facultad de Ciencias Psicológicas.

Barros-Bastidas, C., \& Turpo, O. (2020). La formación en investigación y su incidencia en la producción científica del profesorado de educa- ción de una universidad pública de Ecuador. Publicaciones, 50(2), 167-185. doi:10.30827/publicaciones.v50i2.13952

Barud J. y Labrín (2009). "El dolor invisible de la infancia: Una mirada ecosistémica del maltrato infantil". Editorial Paidós. España.

Bringiotti, María Ines. (2008.) "La violencia cotidiana en el ambito escolar, algunas propuestas posibles de prevención e intervernción"Editorial Lugar. Argentina.

Código de la Niñez y Adolescencia del Ecuador. (2011). Gobierno Provincial del Guayas.

Constitución Política del Ecuador. (2008). Biblioteca Jurídica.

Lázaro, Ángel. (1997). "La función tutorial en la formación docente", Universidad Complutense de Madrid.

España Linares, Juan Luis. (1996). "Identidad y narrativa". Editorial Paidos. Madrid. 57

Marrero, Virginia. (2006) "Intervencion familiar, un enfoque sistémico en la formación de facilitadores" Guayaquil: Facultad de Ciencias Psicológicas.

Minuchin, Salvador. (2009). "Pobreza, institución y familia". Amorrortu edotores. Argentina. 
Programa del Muchacho Trabajador. (2000). "Aprendiendo a educar con amor". PMT. Ecuador. Programa del Muchacho Trabajador. (2000). "Trato es trato, en la familia y en las relaciones educativas

Rodríguez Morales, A., Barros Bastida, C., \& Milanés Gómez, R. (2019). Profesionalización docente y formación desde un nuevo currículo en la Universidad de Guayaquil. Revista Universidad y Sociedad, 11(1), 243248.

von Feigenblatt, Otto Federico, A Socio-Cultural Analysis of Romantic Love in Japanese Harem Animation: A Buddhist Monk, a Japanese Knight, and a Samurai (September 16, 2010). Journal of Asia Pacific Studies, Vol. 1, No. 3, pp. 636-646, 2010, Available at SSRN: $\underline{\text { https://ssrn.com/abstract }=1760643}$

von Feigenblatt, Otto Federico, Costa Rica's Foreign Policy: Can 'Right' Become 'Might'? (November 27, 2008). Journal of Alternative Perspectives in the Social Sciences, Vol. 1, No. 1, pp. 11-15, 2008, Available at

SSRN: https://ssrn.com/abstract=1308245

von Feigenblatt, Otto Federico, Human Security and the Responsibility to Protect: A Holistic Approach to Dealing with Violent Conflict in Southeast Asia (May 13, 2009). Journal of Social Sciences, Vol. 11, No. 1, pp. 27-40, 2009, Available at SSRN: $\underline{\text { https://ssrn.com/abstract }=1570171}$ 